\title{
Yahudi Kaynaklarında Ararat Dağları (Tekvin, 8:4)
}

Yasin MERAL*

The Mountains of Ararat in Jewish Sources (Genesis, 8:4)

Citation/C: Meral, Yasin, (2014). The Mountains of Ararat in Jewish Sources (Genesis, 8:4), Milel ve Nihal, 11 (2), 83-101.

Abstract: The Torah and the Qur'an share many common narrations. The Noah Flood appears as one of these stories. However, it is obvious that the story differs in some details. The most remarkable difference between the narrations is about the place on which the Ark came to rest. While the Qur'an calls the place as al-Judi, the Torah mentions of the Mountains of Ararat. All right, what areas are considered to be the Mountains of Ararat and alJudi? Which places are mentioned in the Jewish sources as the Mountains of Ararat? In this article, the answers of these questions will be sought through first hand sources.

Key Words: Ararat, Judi, Qur'an, Torah, Kardu, Targums, Babylon, Jizrah, Armenia.

Atıf/C: Meral, Yasin, (2014). Yahudi Kaynaklarında Ararat Dağları (Tekvin, 8:4), Milel ve Nihal, 11 (2), 83-101.

Öz: Tevrat ile Kur'an birçok ortak anlatımı intiva etmektedir. Bu anlatımlardan biri de Nuh tufanıdır. Bununla birlikte anlatımların bazı noktalarda farklılaştığı da bilinmektedir. Tufan hadisesinde ilk dikkat çeken husus,

* Yard. Doç. Dr., Ankara Üniversitesi, İlahiyat Fakültesi, Dinler Tarihi Anabilim Dal1 [yasinmeral1979@gmail.com] 
geminin indiği dağla ilgilidir. Kur'an geminin Cudi'ye oturduğunu belirtirken Tevrat Ararat dağlarına oturduğu nakletmektedir. Peki, Ararat ve Cudi isimleri hangi bölgedir? Tarih boyunca Yahudi kaynakları Ararat dağları olarak hangi bölgeler zikredilmiştir? Bu makalede bu sorulara birinci el kaynaklardan cevap aranacaktır.

Anahtar Kelimeler: Ararat, Cudi, Kur'an, Tevrat, Kardu, Targum, Babil, Cizre, Ermenistan.

\section{Giriș}

Orta Doğu coğrafyası barındırdığı tarihi müktesebatla çok istisnai bir bölgedir. Dünya üzerinde bu kadar fazla medeniyete ve kültüre beşiklik eden bir başka yer olmamıştır. İnsanlık tarihinin ilk dönemlerinden itibaren farklı milletler bazen kısa bazen uzun süreli bu coğrafyaya hükmetmiştir. Bu dinamik süreç içerisinde her millet kendinden önceki kültür ve medeniyetlerden etkilenmenin yanı sıra kendine ait değerleri de bu coğrafyaya bırakarak sonradan gelenleri de belirli ölçüde etkilemiştir. Bu anlamda Orta Doğu coğrafyası tek bir milletin kültürünü değil, binlerce yıllık süreç içerisinde onlarca medeniyetin farklı kültürlerini bir potada eriten bir bölge görevi görmüştür. Bugün itibariyle bu coğrafyada yaşayan halklar da binlerce yılın birikiminden oluşmuş gelenekleri çoğunlukla farkında olmadan devam ettirmektedirler.

Medeniyetlerin birbirlerine aktardığı önemli özelliklerden biri de söylencelerdir. Söylencelerin, milletlerin birinden diğerlerine şifahi gelenekle aktarılarak devam ettirilmesi yaygin bir durumdur. Bununla birlikte bir söylencenin farklı milletlerde benzer şekilde yer alması, kronolojik olarak sonradan gelenin önceki medeniyetten aldığı anlamina gelmez. Tufan hadisesi de Orta Doğu'daki birçok medeniyetin ortak anlatımları arasında yer almaktadır. Sözlü olarak hemen hemen her millette yer alan Tufan hadisesi yazılı metin olarak Mezopotamya metinlerinde, Yahudi geleneğinde (Tevrat) ve İslam medeniyetinde (Kur'an) karşımıza çıkmaktadır. Yukarıda da ifade edildiği üzere bu tür ortak anlatımlarda kronolojik olarak önce gelenin hikâyenin kaynağı olduğunu iddia etmek sağlıklı değildir. Orta Çağ'dan başlamak üzere Yahudi din bilginleri Kur'an ve Tevrat arasındaki her ortak anlatımda Kur'an'ın kaynağının Tevrat olduğunu ve Hz. Muhammed'in bilgileri oradan alarak yazdığını iddia etmişlerdir. Onların bu iddialarına göre Hz. Musa'nın da Tufan hadisesini Mezopotamya kaynaklarından almış olması gerekmektedir! 
Tufan hadisesi birçok açıdan incelenmesi gereken bir olaydır. Konuyla ilgili yeterli bilgi olmayışı pek çok sorunun cevapsız kalmasına sebep olmaktadır. Bunun dışında Tevrat ile Kur'an'ın Tufan ile ilgili verdiği bilgilerin farklılıkları da araştırma konusudur. Geminin yapım süreci, gemiye alınan hayvanlar, Nuh'un gemiye binmeyen oğlu ve ihanet eden eşi, geminin oturduğu dağ ve Tufan'ın ne kadar sürdügü bunlar arasında zikredilebilir. Bu makalede, zikredilen bu konulardan Tevrat'ın anlatımına göre geminin oturduğu dağ olarak bahsedilen Ararat isminin Yahudi kaynaklarında nasıl anlaşıldığı incelenecektir. Bu konunun dışında Tufan hadisesiyle ilgili diğer hususlara değinilmeyecektir.

\section{Tevrat'ta ve Kur'an'da Tufan}

Tufan hadisesi, Tevrat'a göre "ilahi varlıkların, insan kızlarının güzelliğini görünce beğendikleriyle evlenmesiyle" başlayan bir sürecin sonucudur. ${ }^{1} \mathrm{Bu}$ evlilikleri müteakiben her türlü ahlaksızlığ1 yapan insanoğlu Tanrı'nın gazabını üzerine çekmiştir. Tevrat'a göre o vakte kadar yüzlerce yıl yaşayan insanların hayatları, yaptıklarından dolayı yüz yirmi yılla sınırlandırılmıştır. ${ }^{2}$ Tevrat bu bilgiyi aktardıktan sonra ilginç bir bilgiyi paylaşmaktadır: "İlahi varlıkların insan kızlarıyla evlenip çocuk sahibi oldukları günlerde ve daha sonra yeryüzünde Nefiller vardı. Bunlar eski çağ kahramanları, ünlü kişilerdi."” 3 İbranice metinde Nefilim olarak geçen Nefiller, mitolojideki düşmüş melek inancıyla ilişkilendirilmektedir. Nefilim kelimesi bazı kaynaklarda düşmüş meleklerin kendileri için bazen de bu semavi varlıkların insan kızlarıyla birlikteliğinden doğan çocuklar için kullanılmıştır. ${ }^{4}$ Tanrı insanların yaptıkları kötülük sebebiyle insanı yarattığına pişman olmuş ve yarattığı her şeyi yeryüzünden silip atacağını ahdetmiştir. ${ }^{5}$

Tevrat'ın Tekvin kitabında anlatılanlara göre Tufan, insanların yoldan çıkmalarının neticesinde Tanrı tarafından takdir edilen bir cezadır. Metinde geçen “Tanrı Nuh'a, insanlığa son vereceğim,

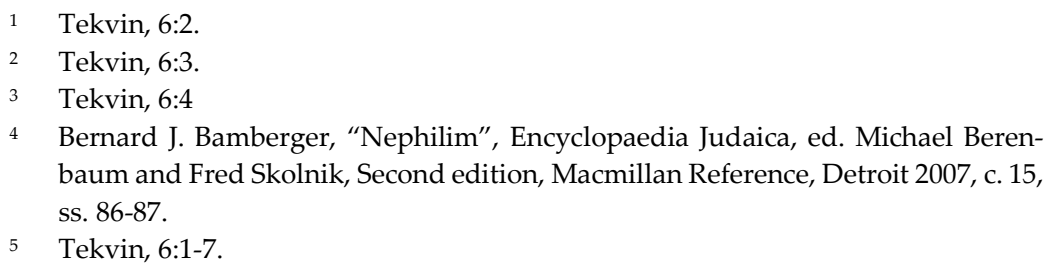


dedi" ${ }^{6}$ ifadeleri bunu teyit etmektedir. Nuh'a gemi yapmasını emreden Tanrı, geminin nasıl yapılacağını detaylı olarak bildirmiştir. Tanrı ayrıca hayvanlardan birer çift ve yemek üzere gıda almasını istemiştir.7 Tevrat'a göre Tanrı, Nuh'a "Yeryüzüne kırk gün kırk gece yağmur yağdıracağım" diyerek Tufan için süre de belirtmiştir. ${ }^{8}$

Tufan başladığında yerin kaynaklarından yeryüzüne sular fışkırmış ve göklerden aralıksız bir şekilde yağmur yağmıştır. Zamanla sular iyice yükselmiş ve yeryüzünde yaşayan bütün canlılar yok olarak sadece Nuh'la birlikte gemidekiler sağ kurtulmuştur. Tevrat'ın nakline göre sular yüz elli gün boyunca yeryüzünde kalmıştır. Sonra Tanrı Nuh'u ve gemidekileri kurtarmak için bir rüzgâr estirmiş ve sular alçalmaya başlamıştır. Akabinde de yerden çıkan sular ve gökten yağan yağmurlar kesilerek sular yeryüzünden çekilmeye başlamıştır. Bunun sonucunda gemi Ararat Dağları'na oturmuştur. ${ }^{9}$ Nuh gemiden çımak için önce kuzgun sonra da güvercin göndererek suların tamamen çekildiğinden emin olmak istemiştir. Güvercin ağzında zeytin yaprağıyla gelince Nuh suların yeryüzünden çekildiğini anlamıştır.10 Nuh, yedi gün daha bekledikten sonra güvercini yine göndermiş bu kez güvercin geri dönmemiştir. Nuh, toprağın kurumuş olduğunu görünce ailesi ve hayvanlarla birlikte gemiden çıkmıştır.

Tevrat'ın bu şekilde naklettiği Tufan kıssası Kur'an'daki anlatılan kıssayla birçok noktada benzerlik göstermektedir. Kur'an'a göre Hz. Nuh, kavminin arasında 950 yıl kalarak tebliğde bulunmuştur. ${ }^{11}$ Fakat bu uzun süreye rağmen kavmi inatla iman etmeye yanaşmamıştır. Hz. Nuh gece gündüz durmaksızın tebliğe devam edip halkı ikna etmeye çalışmışsa da netice alamamıştır. ${ }^{12}$ Bunun üzerine o, insanların yaptıkları ve küstahlıkları karşısında Allah'tan zalimlerin dalaletlerini artırmasını ve yeryüzünde bir tane bile kâfir bırakmamasını dilemiştir. ${ }^{13}$ Allah, Hz. Nuh'a insanların inanmayacaklarını

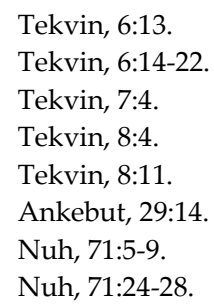


bildirmiş ve gemiyi yapmasını emretmiştir. ${ }^{14}$ Gemi yapımı sırasında ona inanmayan insanların Hz. Nuh'un yanına uğrayarak dalga geçtikleri ve Hz. Nuh'un da "Biz de sizinle dalga geçeceğiz" dediği Kur'an'da zikredilmektedir. ${ }^{15}$ Geminin yapımı bittiğinde Allah, hayvanlardan erkek ve dişi birer çift alarak ailesiyle birlikte gemiye binmesini emretmiştir. Ardından da yerden kaynakların fışkırması gökten de aralıksız yağmurların yağmasıyla Tufan meydana gelmiştir. Hz. Nuh'un oğullarından birisi Hz. Nuh'un ikna çabalarına rağmen onu dinlemeyerek gemiye binmemiş ve suda boğulmuştur. 16

Tufan'ın, insanların günahları sonucunda bir ceza olarak verilmesi hem Tevrat'ın hem de Kur'an'ın verileriyle örtüşmektedir. Tevrat'a göre gemi, en ince ayrıntısına kadar Tanrı'nın rehberliğiyle yapılmıştır. Bu anlatım, Kur'an'da geminin Allah'ın gözetiminde yapıldığı bilgisiyle uyumludur. ${ }^{17}$ Diğer taraftan gemiye binenlerin sınırlı sayıda olması ve hayvan neslinin devamı için birer çift alınması da ortak hususlardandır. Tufan hadisesinin sadece gökten yağan yağmurla değil yerden çıkan kaynak sularıyla oluştuğu bilgisi de Tevrat ve Kur'an'da aynı şekilde anlatılmaktadır. Tufanın sonunda geminin oturduğu dağ ismi ise Tevrat'ta "Ararat dağları" olarak geçerken Kur'an, geminin Cudi'ye oturduğunu belirtmektedir. Dikkat çekici olan husus, Kur'an'ın Cudi'den dağ olarak bahsetmemesidir. Bir diğer ifadeyle Kur'an, geminin "Cudi dağına" değil, "Cudi'ye" oturduğunu aktarmaktadır. ${ }^{18}$

Taberi (ö. 923), tefsirinde Cudi dağının Musul ve Cizre yöresinde olduğunu belirtmektedir. ${ }^{19}$ Cudi dağ 1 adını muhtemelen tarihte bölgede yaşamış Gutilerden (Gutians) almaktadır. ${ }^{20}$ Şırnak ili

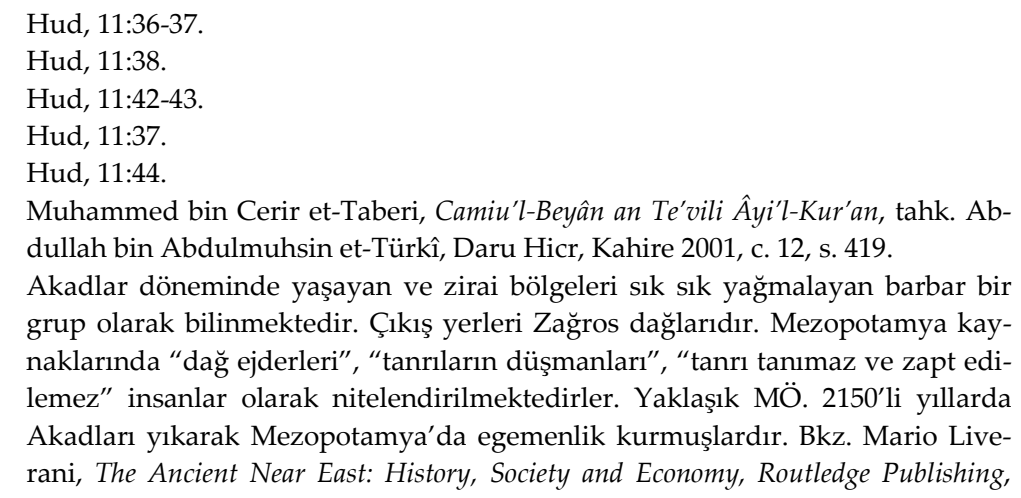
grup olarak bilinmektedir. Çıkış yerleri Zağros dağlarıdır. Mezopotamya kaynaklarında "dağ ejderleri", "tanrıların düşmanları", "tanrı tanımaz ve zapt edilemez" insanlar olarak nitelendirilmektedirler. Yaklaşık MÖ. 2150'li yıllarda Akadları yıkarak Mezopotamya'da egemenlik kurmuşlardır. Bkz. Mario Liverani, The Ancient Near East: History, Society and Economy, Routledge Publishing, 
sınırları içerisinde bugün Cudi dağı olarak bir dağın olması da tarihi bir gerçekliğe işaret etmektedir. Asırlar boyunca gerek şifahi gerekse yazılı olarak aktarılan Tufan hikâyesinde Şırnak yöresinin çevresindeki diğer illere nazaran Hz. Nuh ve Tufan'la ilgili kültürel bir mirasa sahip olması bu anlamda önem arz etmektedir. Şırnak'ta bugün itibariyle Hz. Nuh'a atfedilen bir ziyaretgâh olması, otobüs firmalarından okullarına, otellerinden dağlarına kadar Hz. Nuh'u ve Tufan'ı ifade eden isimler verilmesi şehrin şifahi geleneğinin sürekliliği adına dikkate değer bir durumdur. ${ }^{21}$

Tevrat ve Kur'an'daki Tufan anlatımlarındaki bazı farklılıklar da mevcuttur. Bunlardan en dikkat çekeni Kur'an'a göre Hz. Nuh'un oğullarından birisinin gemiye binmemesidir. Kur'an, Hz. Nuh'un bu oğluyla gemiye binme konusundaki diyalogunu anlatmaktadır. Bu diyalogda Hz. Nuh'un oğlu, yüksek bir dağa çıkarak Tufan'dan kurtulacağını bildirmiş Hz. Nuh da Tufan'dan kaçış olmadığını belirtmiştir. Sonunda aralarına dalgalar girmiş ve oğlu boğulmuştur. Tevrat'a göre Tufan'dan sonra insanlık nesli Hz. Nuh'un gemiye binen üç oğlu Ham, Şem ve Yafet'in aracılığıyla çoğalmıştır. İslam kaynaklarında da Tufan sonrası insan neslinin Ham, Şem ve Yafet aracılığıyla devam ettiği bildirilmektedir. İslam kaynakları bu noktada Hz. Nuh'un, Ham, Şem ve Yafet dişında gemiye binmeyen bir başka oğlunun olduğunu düşünmüşlerdir.

\section{Tevrat Tercümelerinde Ararat Dağı}

Tevrat'ın İbranice metninde Nuh'un gemisinin “Harey Ararat (Ararat Dağları)" üzerine oturduğu belirtilmektedir. Ararat, bugün popüler kültürde Ağrı dağı olarak kabul edilmektedir. Muhtemelen bölgedeki en yüksek dağın Ağrı dağı oluşu Tufan sonrası geminin ilk oturacağ 1 mekân olarak düşünülmesinde etkili olmuştur. Metnin literal anlamı bize bunun sadece bir dağ değil, sıradağlar ya da dağ-

New York 2014, ss. 153-154; Trevor Bryce, Handbook of the Peoples and Places of Ancient Western Asia, Routledge Publishing, Oxon 2009, ss. 265-267. Bu ismin Gurti, Gurdi, Gurdo, Corduene, Kardu kelimeleri arasinda irtibat kurulmakta ve Gutileri bugünkü Kürtlerin muhtemel ataları olarak gören çalışmalar mevcuttur. Bkz. I. E. S. Edwards, C. J. Gadd, N. G. L. Hammond, The Cambridge Ancient History, Cambridge University Press, Cambridge 1971, c. II, s. 444; John Sassoon, From Sumer to Jerusalem, Intellect Books, Oxford 1993, s. 69.

21 Bkz. Ahmet Gülenç, "Nuh Tufanı, Cudi Dağı ve Şehr-i Nuh", Uluslararası Hz. Nuh ve Cudi Dağı Sempozyum Bildirileri, Şırnak Üniversitesi Yayınları, Şırnak 2014, ss. $489-501$. 
lık bir bölge olduğunu göstermektedir. Yahudi kaynaklarında Ararat isminin nasıl anlaşıldığına dair en sağlıklı çözüm ilgili pasaja dair günümüze ulaşmış en eski metinlerin incelenmesidir. Yahudi geleneğinde kronolojik sıraya itibar edilerek metinlerin incelenmesi Ararat ismini anlamamızı kolaylaştıracaktır.

Tevrat'ta geçen özel isimleri açıklamada en sağlıklı kaynak yine Tevrat'ın kendisi olacaktır. Yahudi kutsal metinleri olarak bilinen ve Tora-Neviim-Ketuvim bölümlerinden oluşan Tanah'a baktığımızda Tufan hadisesinin dışında da Ararat kelimesinin kullanıldığı görülmektedir. Bunlardan ilki İsrailoğullarının düşmanı olarak resmedilen Asurlular ile ilgilidir. Tanah'ın II. Krallar ve İşaya kitabına göre Asur kralı Sanherib, Rabbin meleğinin askerlerini öldürmesi üzerine Ninova şehrine çekilir. Sanherib, Ninova'da bir mabedde Nisroh ${ }^{22}$ adlı ilaha tapınırken oğullarından Adrammelek ve Şareser, onu kılıçla öldürüp "Ararat ülkesine" kaçarlar. ${ }^{23}$ Yeremya kitabında da benzer şekilde Ararat ismi bir krallık ismi olarak zikredilmektedir: "Ülkeye sancak dikin! Uluslar arasında boru çalın, ulusları Babil'le savaşmaya hazırlayın. Ararat, Minni, Aşkenaz krallıklarını ona karşı toplayın. Ona karşı bir komutan atayın, çekirge sürüsü kadar at gönderin üzerine!" ${ }^{24}$ Tevrat'ın diğer kitaplarında geçen bu ifadelerden Ararat kelimesinin bir ülke ve bölgeyi ifade etmek için kullanıldığı görülmektedir. Burada kastedilen Ararat ülkesi, tarihte Türkiye'nin güneydoğusu, Suriye, İran ve Irak'ın kuzeyini içine alacak şekilde hüküm süren Urartu devletidir.

En erken dönemlerden itibaren içerisinde Ararat ismi geçen metinlerin incelenmesi önemli olmakla birlikte bu metinlerde geçen Ararat isminin konumuzla ilgisinin tespit edilmesi gerekmektedir. Nuh'un gemisinin indiği Ararat ile ilgisi olmayan fakat aynı veya benzer ismi taşıyan metinlerin bulunması muhtemeldir. Bu safhada en pratik yol, Tevrat'ın "Ararat dağları" ifadesinin dönem dönem farklı dillerdeki tercümelerinde nasıl karşılandığını incelemektir. Tevrat'in en eski Grekçe, Aramice, Latince, Süryanice ve Arapça gibi dillerdeki çevirileri bize "Gemi yedinci ayın on yedinci günü Ararat

\footnotetext{
22 Muhtemelen Nisroh (Nisroch), Hz. Nuh zamanındaki beş puttan biri olan Nesr'dir (Nuh, 71:23).

23 II. Krallar, 19:37; İşaya, 37:38.

24 Yeremya, 51:27.
} 
Dağlari'na oturdu" 25 ifadesinden o dönemin insanlarının ne anlad1ğını gösterecektir. Özel isim olan Ararat kelimesi bütün Tevrat çevirilerinde Ararat şeklinde korunmuş mudur? Farklı bir karşılıkla tercüme edildiyse mütercimler Ararat isminden ne anlamışlardır?

Elimizdeki mevcut bilgileri esas aldığımızda kronolojik olarak bakacağımız ilk çeviri, Tevrat'ın Grekçe çevirisi olan Septuagint'tir. Yetmiş anlamına gelen bu kelime Yahudi kutsal metinlerinin ilk çevirisi olması yönüyle önem arz etmektedir. Grekçe'nin Orta Doğu ve özellikle Mısır' da yaşayan Yahudiler arasında yaygın olarak kullanılması Tanah'ın Grekçe'ye çevrilmesi ihtiyacını doğurmuştur. Geleneğe göre dönemin bölge yöneticisi Ptolemy, İskenderiye'de MÖ. 270'li yıllarda yetmiş veya yetmiş iki Yahudi bilginden Tanah'1 Grekçe'ye tercüme etmelerini istemiştir. Bu olay, Hz. İsa'dan ve İncillerden yaklaşık üç asır önce gerçekleştiği için doğal olarak Septuagint çevirisi sadece Tanah çevirisidir. Fakat o zamanlar itibariyle Tanah'ın kanonizasyonu tamamlanmadığı için günümüzde kanona dâhil olmayan bazı eserlerin de tercüme edildiği görülmektedir. Septuagint çevirisinde Ararat isminin aynı şekilde korunduğu görülmektedir. Ararat ülkesi ifadesine baktığımızda ilgili ifadenin Ermenistan (Armenian) şeklinde tercüme edildiği görülmektedir. ${ }^{26} \mathrm{O}$ dönemler itibariyle Ermenistan diye ifade edilen bölgenin Türkiye'nin doğusu, bugünkü Ermenistan ve Azerbaycan, İran'ın ve Irak'ın kuzeyini kapsadığı bilinmektedir.

Konuya 1şık tutacak metinler arasında Tevrat'ın Aramice çevirileri önemli yer tutmaktadır. Tercüme anlamına gelen Aramice Targum kelimesi, zamanla Tevrat'ın Aramice çevirilerine özel ad olmuştur. Miladın ilk asırlarında Filistin ve Babil yöresindeki Yahudilerin konuşma dili olarak Aramiceyi kullanmalarının neticesinde Tevrat'ın Aramice çevirileri yapılmıştır. Bu asırlarda sinagoglarda Tevrat'ın İbranice metnine ek olarak Aramice çevirisi de okunmuştur. Targum Onkelos olarak bilinen Aramice çevirinin MS. 100-300 yılları arasında hazırlandığına dair farklı tahminler yapılmaktadır. ${ }^{27}$

\footnotetext{
Tekvin, 8:4.

İşaya, 37:38.

27 Targum Onkelos ismiyle anılması da Grek asıllı iken Yahudiliği kabul eden Onkelos isimli bir bilgine nispet edilmesinden dolayıdır. Fakat Onkelos Aramice çeviriyi değil bir başka Grekçe çeviriyi yapan Onkelos Aquila'dır. Targum Onkelos olarak meşhur olan çalışmanın mütercimi belli değildir fakat bu isimle meşhur
} 
$\mathrm{Bu}$ çevirinin herkesçe kabul gören standart Aramice çeviri olduğu ve sinagoglarda okunduğu bilinmektedir. Babil Yahudi akademilerinin Aramice çevirisi olarak bilinen bu çeviri, Babil Targumu olarak da isimlendirilmektedir. Targum Onkelos olarak bilinen bu metinde "Ararat dağları" kelimesinin nasıl karşılandığına baktığımızda “Turey Kardu" ifadesiyle karşılaşmaktayız. ${ }^{28}$ Tur kelimesi Aramicede dağ anlamına gelmektedir ki Kur'an da bu kelimeyi aynı anlamda kullanmaktadır (Tûr-u Sina). Kardu kelimesi ise Ararat yerine karş1lanan isimdir. Kardu ismi tarihi olarak bugünkü Irak-Suriye-Türkiye'nin sınır bölgeleri için kullanılmaktadır. ${ }^{29}$ Muhtemelen Kürd kelimesi de bu isimden gelmektedir. Bu durumda miladın ilk asırlarında Irak'taki Yahudiler, Ararat ismiyle coğrafyasını iyi bildikleri Irak'ın kuzeyini ve Türkiye'nin güneydoğusunu anlamışlardır.

Targum Onkelos olarak bilinen çevirinin dişında Tevrat'ın başka Aramice tercümeleri de mevcuttur. Bunlardan biri de Targum Neofiti olarak bilinmektedir. Targum Neofiti, metod olarak literal çeviri yapan Onkelos ile tefsirî çeviri yapıp metne açıklamalar giren Targum Yonatan arasında orta yol bir çeviri tarzına sahiptir. Targum Yonatan gibi Filistin yöresine ait bu Targum, MS. 100-400 aras1 bir dönemle tarihlendirilmektedir. Bu çeviride de Ararat dağları ifadesi "Kardun dağları" olarak tercüme edilmiştir. ${ }^{30} \mathrm{Bu}$ şekilde bir karşılık Targum Onkelos'la uyumlu olup aynı bölgeye işaret etmektedir.

Tevrat'ın bir başka Aramice çevirisi de Filistin yöresinde kaleme alınan Targum Yeruşalmî'dir. ${ }^{31}$ Ana metni miladın ilk asırlarında hazırlanan bu çeviriye İslam'ın ortaya çıkışından sonra

olmuştur. Karışıklığa sebebiyet vermemek için Targum Onkelos olarak kullanılacaktır.

28 Targum Onkelos, Bereşit, 8:4 (ed. Moses Aberbach-Bernard Grossfeld, Ktav Publishing House, Denver 1982, s. 61)

29 Bu isim; Kardu, Cardo, Cardunia, Cordyene, Cardyene, Carduene, Gorduene, Gordyene gibi farklı şekillerde karşımıza çıkmaktadır. Genellikle Van gölüyle Musul arasında bölgeyi ifade etmek için kullanılmıştır.

30 Targum Neofiti 1: Genesis, 8:4 (ed. Alejandro Diez Macho, Consejo Superior de Investigaciones Cientificas, Madrid-Barcelona 1968, s. 43; trans. Martin McNamara, Liturgical Press, Minnesota 1992, s. 77)

31 Bu Targum yaygın adıyla Targum Yonatan olarak bilinmektedir. Fakat Targum Yonatan, Tanah'ın Neviim bölümünün Aramice çevirisidir. Bununla birlikte Yonatan ben Uziel'e atfedilen Tevrat bölümünün çevirisi de mevcuttur. Fakat bu 
eklemelerin yapıldığı görülmektedir. ${ }^{32} \mathrm{Bu}$ tercümede Ararat dağlarryla ilgili pasaj şu şekilde Aramiceye çevrilmiştir: "Gemi, Kardun dağlarına oturmuştur. Dağın birinin adı Kardanya diğerinin adı ise Arminya'dır. Orada doğu topraklarında Armanya isimli şehir kurulmuştu." 33 Görüldügüü üzere bu Targum'un çevirisi literal değil tefsiri çeviridir ve metinde yer almayan bilgileri de açıklama olarak çeviride yer vermektedir. Babil yöresindeki Targum Onkelos'a benzer şekilde Filistin yöresine ait bu Targum da Ararat ismini Kardun olarak çevirmektedir. Kardun dağları olarak bilinen yerin Irak-Suriye-Türkiye sınırındaki dağlık bölgeler olduğu yukarıda ifade edilmişti. Böylelikle bir başka erken dönem kaynağı da aynı bölgeyi işaret ettiği görülmektedir. Yine metinde geçen Kardanya, Kardu'yla aynı kökten gelen bir başka isimlendirmedir. Arminya ya da Armanya da Ermenistan için kullanılmaktadır.

Konuyla ilgili bakılabilecek bir diğer önemli kaynak da Yahudiliğin önemli bir grubu sayılan Samirilere ait temel kaynaklardır. Bilindiği üzere Samirilerin kullandığı Tevrat'la Rabbani Yahudilerin kullandığı Tevrat arasında pek çok farklılıklar bulunmaktadır. Samiri Tevratı Ararat kelimesini ince -he sesi eklenmiş şekilde $\mathrm{Ha}$ rarat olarak kaydetmektedir. ${ }^{34} \mathrm{Bu}$ anlamda aynı kelimenin farklı bir telaffuzu olduğunu söylemek mümkündür. Rabbani gelenekte olduğu gibi Samiriler arasında da Tevrat'ın Aramice çevirileri kullanılmaktaydı. Günümüze ulaşan Samiri Targumu iki ana kaynak aracılı̆̆ıyla gelmiştir. Bu iki metin arasında farklılıklar mevcuttur.

çeviri ona ait olmadığg için yanlış bir şekilde Yonatan'a atfedilen anlamında Pseudo-Yonatan olarak isimlendirilmektedir. Akademik çevrelerde bu çeviri Filistin Targumu ya da Kudüs Targumu olarak bilinmektedir.

32 Metinde olmadığı halde Aramice çeviride bazı İslami isimlerin metne eklendiği görülmektedir. Örneğin bu Targum'a göre Hacer'in, oğlu İsmail'i evlendirmesinden bahseden "Paran Çölü'nde yaşarken annesi ona Mısırlı bir kadın aldı." ifadesi "O (İsmail) kendine Adişe (Ayşe) adında bir kadın aldı, sonra onu boşadı ve annesi ona Mısır diyarından Fatıma adında bir kadın aldı" şeklinde tercüme edilmiştir. Ayşe ve Fatıma isimlerinin metne İslam sonrası dönemde eklendiği açıktır. Aynı olay Pirke de-Rabbi Eliezer'de de görülmektedir. Bkz. "Pirke Rabbi Eliezer", ed. Michael Higger, Horeb 10 (1948), ss. 192-193.

33 Targum Pseudo-Jonathan: Genesis, 8:4 (trans. Michael Maher, Liturgical Press, Minnesota 1992, Genesis, 8:4, s. 42.)

34 Hamişa Humşey Tora: Nusah Şomron ve-Nusah Masora, Bereşit, 8:4 (ed. Avraham Tal-Moshe Florentin, The Haim Rubin Tel Aviv University Press, Tel Aviv 2010, s. 77) 
Ararat kelimesi bu nüshalardan birinde tivrey Hararat şeklinde görülürken diğerinde tivrey Serendib ${ }^{35}$ şeklinde ortaya çıkmaktadır. Hararat şeklinde karşılanan çevirinin, İbranice Samiri Tevrat'ındaki Hararat' 1 aynı şekilde koruduğu görülmektedir. Dikkat çeken husus ise diğer nüshanın Ararat kelimesini Serendib olarak karşılamasıdır. Bilindiği üzere Serendib Hindistan'ın doğusundaki Sri Lanka adası için kullanılan eski bir isimlendirmedir. Samirilerin temel külliyatında bakacağımız bir diğer kaynak da Arapça Tevrat tercümesidir. Bu çeviri, 13-14. asırlara aittir. İlginç bir şekilde Samirilerin Arapça Tevrat çevirisinde Ararat/Hararat dağları ifadesi Cibâl-i Serendib olarak tercüme edilmiştir. ${ }^{36}$

Tevrat tercümeleri arasında önemli bir yer tutan bir başka çeviri de Yahudi âlim Saadya Gaon'a (ö. 942) ait Tevrat tercümesidir. M1sır'da doğan ve ömrünün büyük bir kısmını Bağdat'da geçiren Saadya, Tevrat'ın tamamını Arapça'ya çeviren ilk Yahudi bilgindir. Saadya, Arapça çevirisinde Ararat dağı ifadesini Targumlarla uyumlu olarak Cibal-i Karda şeklinde tercüme etmektedir. ${ }^{37}$ Onun bu çevirisi kendi dönemindeki genel kabulü göstermesi açısından önem arz etmektedir. Nitekim Saadya ile aynı asırda yaşamış İslam coğrafyacılarından Makdisî de aynı şekilde Nuh'un gemisinin Karda'ya indiğini nakletmektedir. ${ }^{38}$

Tevrat'ın Süryanice çevirisi olarak bilinen Peşita da konumuzla ilgili bize fikir vermektedir. İkinci asırla tarihlendirilen Peşita, Süryani gelenek içerisinde Tevrat'ın ilk Süryanice çevirisi olarak bilinmektedir. Bu çeviride "Ararat dağları" ifadesinin Kardo dă̆ları (Turey Kardo) olarak tercüme edildiği görülmektedir. ${ }^{39} \mathrm{Bu}$ da yine yukarıda Yahudiler arasında genel kabul gören çevirilerle uyum göstermektedir. Miladi ilk asırların çevirileri dikkate alındığında o dönemin insanlarının Ararat isminden Türkiye-Irak sınırındaki dağlık bölgeyi anladıkları ve bu konuda genel bir kabul olduğu

35 ha-Targum ha-Şomronî le-Tora, Tekvin, 8:4, (ed. Avraham Tal, Telaviv University Press, Telaviv 1980, c. I, ss. 24-25.)

36 Hasib Şehade, et-Tercemetü'l-Arabiyye li-Tevrati's-Samiriyyin, ha-Akademya haLeumit ha-Yisraelit le-Madaim, Kudüs 1989, Tekvin, 8:4, c. I, s. 32.

37 Saadya Gaon, Tefsiru't-Tevriye bi'l-Arabiyye, Tekvin 8:4, (ed. Naftali Yosef Derenbourg, Paris 1893, s. 14)

38 Mutahhar b. Tâhir el-Makdisî, Kitâbu'l- Bed' ve't- Târîh, tahk. C. Huart, Paris, 1903, c. 3 , s. 24 .

39 Tekvin, 8:4 (Ktobo Kadişo, United Bible Society, Damascus 1979, s. 6.) 
açıkça görülmektedir. Hıristiyanlara ait erken dönem çevirilerinden Vulgate de konuyla ilgili fikir vermektedir. Jerome tarafından MS. 405 yılında tamamlanan bu çeviride Ararat dağları ifadesi, Ermenistan dağları (montes Armeniae) olarak çevrilmektedir.

Tevrat'ta Ararat olarak geçen isimlendirme Asur kaynaklarında Urartu olarak zikredilmiştir. ${ }^{40}$ MÖ. VI. Asırdan itibaren Ermenilerin bölgeyi ele geçirmelerinin ardından bölge Ermenistan olarak meşhur olmuştur. Kur'an'ın bahsettiği Cudi kelimesi ise adını muhtemelen MÖ. 2000'li yılların ilk asırlarında Akkadlıların kontrolü altında yaşayan Gutiler'den almaktadır. Kaynaklarda ziraî bölgeleri yağmalayan barbar insanlar olarak aktarılan bu grup Cudi dağına da ismini vermiştir.

\section{Yahudi Dini Literatüründe Ararat Dağı}

Ararat dağının nasıl anlaşıldığına dair fikir sahibi olacağımız başka Yahudi kaynakları da mevcuttur. Bunlar arasinda Tevrat tefsirleri, Yahudi tarihi kitapları, seyahatnameler sayılabilir. Bu bölümde Tevrat dışı Yahudi dini literatürde Ararat dağıyla ilgili kaynaklar kronolojik sırayla incelenecek ve Tevrat çevirileriyle ne derece uyumlu oldukları hakkında fikir sahibi olunacaktır.

Tanah dışı metinlerden ele alınacak ilk metin Yubileler kitabıdır. Elli bölümden oluşan metin, bir anlamda Tekvin kitabının bir başka versiyonu gibidir. Bugün Yahudi kanonunun dışında kalan bu kitaba göre Nuh'un gemisinin indiği yer, Lubar dağıdır. Metne göre Lubar, Ararat dağlarından birinin adı veya sıradağlar silsilesinin zirvesidir. ${ }^{41}$ Bunun dışında Lubar dağının doğusunda Sadakat Levav; güneyinde Nahalat Emek; batısında da Adotan Yelek isimli üç farklı yerleşim bölgesinden bahsedilmektedir. Bu isimler sırasıyla Şem, Ham ve Yafet' in eşleri olarak geçmektedir. Tufan sonrası bir müddet babalarıla yaşayan çocuklar belli bir zamandan sonra

\footnotetext{
40 Tikva S. Frymer-S. David Sperling, "Ararat", Encyclopaedia Judaica, ed. Michael Berenbaum-Fred Skolnik. 2nd ed., Macmillan Reference, Detroit 2007. c. 2, ss. 360-361.

41 Yubileler Kitabi, 5:28, 7:1.
} 
her biri o bölgenin ayrı bir yerine giderek yeni şehirler kurmuşlardır. ${ }^{42}$ Yubileler kitabı ayrıca Nuh'un öldüğünde Lubar dağına gömüldüğünü de aktarmaktadır. ${ }^{43}$ Burada Lubar'ın Ararat ismi yerine alternatif olarak kullandığı görülmektedir. Fakat Lubar'la ilgili yeterli bilgi bulunmamaktadır. Modern dönem araştırmacılar da Lubar'ın Ararat yerine kullanılan bir isim olduğunu belirtmekle yetinmişlerdir. ${ }^{44}$ Bazı Kumran parşömenlerinde de Lubar dağı Hz. Nuh'un tufan sonrası üzüm bağı diktiği dağ olarak görülmektedir. ${ }^{45}$

Ararat dağı hakkında bilgi bulunan bir başka tarihi kayıt da Yahudi tarihçi Yosefus'un (ö. 100) Yahudilerin tarihini ele aldığ1 eseridir. Yosefus, eserinde Ararat dağlarının yerini Ermenistan olarak vermektedir. ${ }^{46}$ Yosefus'un bu eseri kaleme aldığı dönemde Irak'1n kuzeyi de bugünkü Ermenistan da Ermenistan coğrafyası içerisinde yer almaktadır. Bu anlamda bu ifade çok geniş bir coğrafyayı işaret etmektedir. Fakat Yosefus, bununla yetinmemekte ve Keldani tarihçi Berosus'un Ararat için Ermenistan'daki Kardunya dağlarını anladığını nakletmektedir. ${ }^{47}$ İbrani Üniversitesi profesörlerinden Cassuto, Yosefus'un Berosus'tan yaptığı alıntıda geçen Kardunya dağlarını Kürd Dağları şeklinde açıklamaktadır. ${ }^{48}$

En erken dönemlerden itibaren Tevrat'ın anlaşılmasına yönelik kaleme alınan eser türlerinden biri de midraşlardır. Bunlar arasında miladi 4-5. asırlarda kaleme alınan ve Tevrat'ın Tekvin kitabı hakkında açıklamaların yer aldığı Bereşit Raba önem arz etmektedir. Bu esere baktığımızda Ararat dağlarının “Turey Kardunya” ifadesiyle

42 Yubileler Kitabı, 7:14-17. Bu isimler İngilizce kaynaklarda Sedeqetelebab, Ne'elatama'uk ve Adataneses şeklinde geçmektedir.

43 Yubileler Kitabi, 10:15.

44 Bazı araştırmacılar bölgedeki ay kültünden ötürü Lavan (beyaz=ay) kelimesine nispetle bazen Luban şeklinde bazen de çıkış yeri anlamında eski Ermenicedeki Lubar'a dayandırmışlardır. Bkz. George Stanley Faber, The Origin of Pagan Idolatry, London 1816, s. 387.

45 Bkz. Joseph Fitzmayer, The Genesis Apocryphon of Qumran Cave 1 (1Q20): A Commentary, Editrice Pontificio Istituto Biblico, Roma 2004, s. 161. Krş. Tekvin, 9:20.

46 Josephus, The Antiquities of the Jews, 1.3.5. (William Whiston, Josephus: The Complete Works, Thomas Nelson Publishers, Nashville 1998, s. 38)

47 Josephus, The Antiquities of the Jews, 1.3.6, s. 39.

48 U. Cassuto, Peruş ha ha-Tora: Bereşit, The Magnes Press, Jerusalem 1974, s. 72. 
karşılandığı görülmektedir. ${ }^{49} \mathrm{Bu}$ bilgi de aynı dönemde kaleme alınmış gerek Filistin coğrafyasında gerekse Babil'deki diğer eserlerle örtüşmektedir.

Yahudilerin Tevrat'tan sonra en fazla değer verdikleri ikinci metin olan Babil Talmudu'nda (MS. 500-550) Ararat dağıyla ilgili bilgi yer almamaktadır. Fakat konuyla ilişkilendirebilecek önemli bir bilgiye yer verilmektedir. Irak'taki Yahudi âlimlerin yorum ve tecrübelerini içeren Babil Talmudu, bölgede Karduyim (Kürtler?) şeklinde isimlendirilen bir topluluktan bahsetmektedir. Buna göre Karduyim'den Yahudiliği kabul edenlerin Yahudi cemaatine kabul edileceği belirtilmektedir. Aynı bölümde Kartuyim adıyla bir gruptan daha bahsedilmekte ve bunlar arasından Yahudiliği seçecek olanların cemaate kabul edilmeyeceği dile getirilmektedir. Kartuyim ile Karduyim arasında ne fark olduğuna dair bir soruyla devam eden metin, bunların her birinin farklı insan grupları olduğunu belirterek Kartuyim adlı insanların problemli/arızalı insanlar olduğu şeklinde bir açıklamaya yer vermektedir. ${ }^{50}$ Görüldüğü üzere açıklamada bölgede Karduyim adıyla bir insan grubundan bahsedilmekte ve muhtemelen pratik gerekçelerden dolayı ihtidaları tartışılmaktadır. Her ne kadar Ararat dağıyla ilgili bilgi içermese de miladi altıncı yüzyılın başlarında bugünkü Irak'ta derlenen Babil Talmudu'nun Karduyim kelimesiyle Kardu/Kardunya isimlerine 1şık tuttuğu söylenebilir.

Nuh Tufanı ve geminin nereye indiği hususlarında konumuza aydinlatacak kaynaklardan biri de seyahatnamelerdir. Bunlar arasında en meşhuru şüphesiz on ikinci asırda Orta Doğu'daki Yahudi cemaatler hakkında önemli bilgiler aktaran Yahudi gezgin Tudelalı Benyamin'in seyahatnamesi gelmektedir. ${ }^{51}$ Gezdiği şehirlerdeki Yahudilerin nüfusları, etkileri ve kültürel yaşamlarıyla ilgili bilgiler veren Benyamin aynı zamanda o şehirlerin tarihi arka planlarına dair önemli bilgileri de paylaşmaktadır. Bu çerçevede konumuzla ilgili olması açısından Ceziretü İbn Ömer adlı yerleşim bölgesinde

49 Bereşit Raba, 33:4 (The Midrash Rabbah, trans. H. Freedman-Maurice Simon, The Soncino Press, London-Jerusalem-NewYork 1977, c. I, s. 264)

50 Talmud Bavli, Yevamot, 16a.

51 Bu eser Türkçeye çevrilmiştir. Bkz. Nuh Arslantaş, Orta Çă̆da İki Yahudi Seyyahın İslam Dünyası Gözlemleri, Marmara Üniversitesi İlahiyat Fakültesi Vakfı Yayınları, İstanbul 2009. 
yaşayan Yahudilerden bahsettiği bölümde şehrin Hz. Nuh'un gemisinin oturduğu Ararat dağlarının hemen yanında konuşlandığını belirtmektedir. ${ }^{52}$ Arapça kaynaklarda Ceziretü İbn Ömer ya da sadece Cezire olarak geçen yerleşim bölgesi, Irak-Türkiye-Suriye s1nırlarının birleştiği yerde bulunan Cizre'dir. ${ }^{53}$ Bazı Yahudi kaynaklarında Ceziretü İbn Ömer doğrudan Kardu ismiyle özdeşleştirilmektedir. Nitekim İslam coğrafyacıları da Cudi'nin Cizre'de olduğunu ve Karda ismiyle bilinen dağlarda yer aldığını belirtmişlerdir. ${ }^{54}$ Kardu, Kardo, Kardunya, Kurdanayta ve Kardun gibi farklı isimlerle karşımıza çıkan isim, geniş anlamda Van gölüyle Musul arasını özelde de Şırnak-Cizre yöresini ifade etmektedir. Talmud döneminde (MS. 3-6 asırlar) Irak'taki Yahudi yerleşim bölgelerini ele aldığı eserinde Eshel, Kardu'yu Ceziretü İbn Ömer'le ilişkilendirme ve Kürdistan olarak açıklamaktadır. ${ }^{55}$

Ararat'la ilgili açıklamalara Tevrat tefsirlerinde de rastlanmaktadır. ${ }^{56}$ Bunlardan biri de Nahmanides'e (ö. 1270) ait Tevrat tefisiridir. Ararat dağları ifadesini, Ararat ülkesi tabiriyle ilişkilendiren Nahmanides, bu bölgenin Babil yakınlarında olduğunu belirtmektedir. ${ }^{57}$ Babil ismiyle özelde Bağdat yöresi daha geniş anlamda da Irak'ın kastedildiği bilinmektedir. Bu anlamda Nahmanides'in açıklamaları da gelenekteki açıklamaların devamı niteliğindedir. Yemenli Yahudi bilginlerden Natanel ben Yeşayahu da (14. yy) Tevrat'a yazdığı Nuru'z-Zalam isimli Judeo-Arabic tefsirde Ararat ismini Onkelos'un Aramice çevirisini esas alarak açılamakta, çok yüksek ve soğuk bir mekân olduğu için İbranice/Aramicedeki Kar

52 Masaot Benyamin, ed. Simha Yehaşua, Migdale Ernan, Yeruşalayim 2010, s. 25.

53 Metin Tuncel-Abdulkerim Özaydın, "Cizre", Diyanet İslam Ansiklopedisi (DİA), Diyanet Vakfı Yayınları, İstanbul 1993, c. 8, ss. 37-39.

54 Hanefi Palabıyık, "Klasik İslam Coğrafyacılarına Göre 'Ağrı Ve Cûdî Dağları'", Güzel Sanatlar Enstitüsü Dergisi 19 (2007), ss. 169-172. Ayrıca bkz. Eliyahu Ashtor, "Jazirat ibn 'Umar", Encyclopaedia Judaica, ed. Michael Berenbaum and Fred Skolnik. 2nd ed., Macmillan Reference, Detroit 2007, c. 11, s. 98.

55 Ben-Zion Eshel, Yişuvey ha-Yehudim be-Bavel be-Tekufat ha-Talmud (Talmud Zamanında Babil'de Yahudi Yerleşim Bölgeleri), Magnes Press, Yeruşalayim 1979, ss. 228-229.

56 Orta Çă̆’a ait hemen hemen bütün tefsirleri gözden geçirmeye çalıştık. Ararat ismiyle ilgili açıklama yapmayan tefsirler zikredilmemiştir.

57 Peruş ha-Ramban al ha-Tora, ed. Menahem Mendel Goldberg, Hotsaat Nehora, 2009, c. I, s. 43; Ramban Commentary on the Torah, trans. Charles Chavel, Shilo Publishing House, New York 1971, s. 126. 
(soğuk) isminden dolayı dağın Kardu ismiyle anıldığını belirtmektedir. ${ }^{58}$ Eseri tahkik eden Yosef Kafih (ö. 2000) ise Onkelos'taki “Turey Kardu (Kardu dağları)” ifadesinin “Turey Kurdistan (Kürdistan dağları)" anlamına geldiğini belirtmektedir. ${ }^{59} \mathrm{Bu}$ ifadeler de gelenekteki açıklamaları teyid mahiyetindedir.

Konumuza 1şık tutacak bir diğer kaynak da İbranice Kur'an mealleridir. Hud suresinde Hz. Nuh'un gemisinin indiği yer olarak zikredilen Cudi'nin Yahudi araştırmacılar tarafından hazırlanan İbranice meallerde nasıl karşılandığı bize fikir verecektir. 1857 yılında Haim Zvi Reckendorf tarafından Arapça orijinal metinden İbraniceye tercüme edilen mealde Cudi kelimesi özel isim olarak alınarak aynı şekilde korunmuştur. Fakat Reckendorf, Kur'an metninde olmadığ1 halde ilgili ifadeye dağ kelimesini ekleyerek "Har Cudi (Cudi Dağ1)" şeklinde tercüme etmiştir. Bu kelimeye düşülen dipnotta ise Reckendorf, bununla Ararat dağının kastedildiğini belirtmiştir. ${ }^{60}$ İlginç bir şekilde Reckendorf, burada herhangi bir polemiğe girerek Kur'an'ın Tevrat'tan farklı olarak Cudi şeklinde bilgi verdiğini, doğrusunun Ararat olması gerektiği gibi savunmacı açıklamalara girmemektedir. Bilakis Kur'an'daki Cudi'nin Ararat olduğunu belirtmektedir. Daha açık ve net bir tercih ise 1968 tarihli Aharon ben-Şemeş'in mealinde yer almaktadır. O, ilgili ayeti “Gemi Ararat dağlarında bulunan Cudi dağı oturdu (ha-har el-Cûdî şe-be-harey Ararat)" şeklinde tercüme etmektedir. Dipnotta ise Cudi dağının Ermenistan ile Irak arasında olduğu, Bereşit Raba isimli midraşta da Turey Kardunya şeklinde bilgi yer aldığı nakledilmektedir. ${ }^{61}$ Ben-Şemeş'in ayetin tercümesine Ararat kelimesini ekleyerek tek cümlede iki bilgiyi mezcetmesi Yahudi geleneğinin en iyi özeti olarak değerlendirebilir. ${ }^{62}$

58 Natanel ben Yeşayahu, Nuru'z-Zalâm, tahk. Yosef Kafih, ha-Aguda le-hatslat Ginzey Teyman, Yeruşalayim 1967, s. 65.

59 Natanel ben Yeşayahu, Nuru'z-Zalâm, s. 65, dipnot 3.

60 Hud, 11:44 (Haim Reckendorf, ha-Kuran o ha-Mikra, Leipzig 1857, s. 127)

61 Hud, 11:44 (Aharon ben-Şemeş, al-Kur'an, Hotsaat Sfarim Karni, Yeruşalayim 1968, s. 132.)

62 Kaynaklara göre Ararat ve Cudi, aynı bölgenin farklı dönemlerdeki isimleridir. Gutilerle Urartuların yaşadığı dönemler ve Kutsal Kitap araştırmacılarının Tufan için verdikleri tahmini tarihler karşılaştırıldığında Cudi isminin Tufan'ın olduğu dönemdeki ismi olduğu, Ararat-Urartu ve Ermenistan isimlerinin ise ilgili metinlerin kaleme alındığı dönemde kullanılan isimler oldukları anlaşılmaktadır. 


\section{Sonuç}

Nuh'un gemisinin oturduğu dağ olarak zikredilen Ararat'ın en erken dönemlerden itibaren nasıl anlaşıldığı Yahudi kaynaklarındaki en eski metinleri incelemekle mümkündür. Zira kaynağına daha yakın olmaları sebebiyle, Tevrat'ı anlama noktasında günümüz insanından daha şanslı oldukları şüphe götürmez bir gerçektir. Bu anlamda onların Ararat kelimesine verdikleri anlamlar bize yardımcı olmaktadır. Bu sayede biz 2000 yıl önce miladın ilk asrında yaşayan bir Yahudi bilginin Tevrat'ı Aramiceye çevirirken Ararat kelimesine verdiği karşılığa bakarak bir fikir edinebilmekteyiz.

Tevrat'ın bilinen ilk çevirisi Septuagint'ten başlamak üzere Yahudi kaynakları, Ararat ifadesiyle bugünkü Irak-Suriye-Türkiye sınırındaki dağlık bölgeleri anlamışlardır. Bu bölgenin tarih boyunca Gutiler, Urartu, Ermenistan gibi farklı devletlerin egemenliğinde olduğu bilinmektedir. Bu da Ermenistan isimlendirmesinin modern Ermenistan devletinin sınırlarıyla karıştırılmaması gerektiğini ortaya koymaktadır. Zira tarihte Ermenistan'ın sınırlarının bugünkü toprakları da dâhil olmak üzere Türkiye'nin doğusu Suriye, Irak ve İran'ın kuzeyini içine aldığı bilinmektedir. Özetle, Yahudi kaynaklarının Tevrat'ta geçen "Ararat dağları" ifadesinden anladıkları yer ile İslam kaynaklarının Kur'an'da geçen "Cudi" isminden anladıkları yer aynı bölgedir.

\section{Kaynakça}

Arslantaş Nuh, Orta Çă̆da İki Yahudi Seyyahın İslam Dünyası Gözlemleri, Marmara Üniversitesi İlahiyat Fakültesi Vakfı Yayınları, İstanbul 2009.

Ashtor, Eliyahu, “Jazirat ibn 'Umar", Encyclopaedia Judaica, ed. Michael Berenbaum and Fred Skolnik, 2nd ed, Macmillan Reference, Detroit 2007, c. 11, s. 98.

Bamberger, Bernard, “Nephilim”, Encyclopaedia Judaica, ed. Michael Berenbaum and Fred Skolnik, 2nd ed, Macmillan Reference, Detroit 2007, c. 15 , ss. $86-87$.

Ben Shemesh, Aharon, ha-Kur'an, Hotsaat Sfarim Karni, Telaviv 1968.

Ben-Zion Eshel, Yişuvey ha-Yehudim be-Bavel be-Tekufat ha-Talmud, Magnes Press, Yeruşalayim 1979.

Bryce, Trevor, Handbook of the Peoples and Places of Ancient Western Asia, Routledge Publishing, Oxon 2009.

Cassuto, U., Peruş ha-Tora: Bereşit, The Magnes Press, Jerusalem 1974.

Dartma, Bahattin, "Nûh (a.s)'un Gemisini Demirlediği Yere Dair", Kur'an Mesajı: İlmi Araştırmalar Dergisi, 2/ 13,14,15 (1999), ss. 140-146. 
Edwards, E. S., C. J. Gadd, N. G. L. Hammond, The Cambridge Ancient History II, Cambridge University Press, Cambridge 1971.

Faber, George Stanley, The Origin of Pagan Idolatry, London 1816.

Feyyumi, Said bin Yusuf (Saadya Gaon), Tefsiru't-Tevriye bi'l-Arabiyye, ed. Naftali Yosef Derenbourg, Paris 1893.

Fitzmayer, Joseph, The Genesis Apocryphon of Qumran Cave 1 (1Q20): A Commentary, Editrice Pontificio Istituto Biblico, Roma 2004.

Frymer, Tikva-David Sperling, "Ararat", Encyclopaedia Judaica, ed. Michael Berenbaum-Fred Skolnik, 2nd ed, vol. 2, Macmillan Reference, Detroit 2007, ss. 360-361.

Gülenç, Ahmet, "Nuh Tufanı, Cudi Dağı ve Şehr-i Nuh", Uluslararası Hz. Nuh ve Cudi Dağı Sempozyum Bildirileri, Şırnak Üniversitesi Yayınları, Şırnak 2014, ss. 489-501.

Hamişa Humşey Tora: Nusah Şomron ve-Nusah Masora, ed. Avraham TalMoshe Florentin, The Haim Rubin Tel Aviv University Press, Tel Aviv 2010.

Josephus, The Antiquities of the Jews, William Whiston, Josephus: The Complete Works, Thomas Nelson Publishers, Nashville 1998.

Ktobo Kadişo, United Bible Society, Damascus 1979.

Liverani, Mario, The Ancient Near East: History, Society and Economy, Routledge Publishing, New York 2014.

el-Makdisî, Mutahhar b. Tâhir, Kitâbu'l- Bed' ve't- Târîh, tahk. C. Huart, Paris, 1903.

Masaot Benyamin, ed. Simha Yehaşua, Migdale Ernan, Yeruşalayim 2010.

Midrash Rabbah, trans. H. Freedman-Maurice Simon, The Soncino Press, London-Jerusalem-NewYork 1977.

Palabıyık, Hanefi, “Klasik İslam Coğrafyacılarına Göre Ağrı Ve Cûdî Dağları”, Güzel Sanatlar Enstitüsü Dergisi 19 (2007), ss. 155-175.

Peruş ha-Ramban al ha-Tora, ed. Menahem Mendel Goldberg, Hotsaat Nehora, 2009.

Pirke Rabbi Eliezer, ed. Michael Higger, Horeb 10 (1948), ss. 185-204.

Ramban Commentary on the Torah, trans. Charles Chavel, Shilo Publishing House, New York 1971.

Reckendorf, Haim, al-Kur'an o ha-Mikra, Leipzig 1857.

Sassoon, John, From Sumer to Jerusalem, Intellect Books, Oxford 1993.

Şehade, Hasib, et-Tercemetü'l-Arabiyye li-Tevrati's-Samiriyyin, ha-Akademya ha-Leumit ha-Yisraelit le-Madaim, Kudüs 1989.

Taberi, Muhammed bin Cerir, Camiu'l-Beyân an Te'vili Âyi'l-Kur'an, tahk. Abdullah bin Abdulmuhsin et-Türkî, Daru Hicr, c. 12, Kahire 2001.

Tanyu, Hikmet, "Cudi Dağı", Diyanet İslam Ansiklopedisi (DİA), Diyanet Vakf1 Yayınları, İstanbul 1993, c. 8, ss. 79-80. 
Yahudi Kaynaklarında Ararat Dağları (Tekvin, 8:4)

ha-Targum ha-Şomronî le-Tora, ed. Avraham Tal, Telaviv University Press, Telaviv 1980.

Targum Neofiti 1: Genesis, ed. Alejandro Diez Macho, Consejo Superior de Investigaciones Cientificas, Madrid-Barcelona 1968.

Targum Neofiti 1: Genesis, trans. Martin McNamara, Liturgical Press, Minnesota 1992.

Targum Onkelos, Bereşit, ed. Moses Aberbach-Bernard Grossfeld, Ktav Publishing House, Denver 1982.

Targum Pseudo-Jonathan: Genesis, trans. Michael Maher, Liturgical Press, Minnesota 1992.

Tuncel, Metin-Abdulkerim Özaydın, "Cizre", Diyanet İslam Ansiklopedisi (DIA), Diyanet Vakf1 Yayınları, İstanbul 1993, c. 8, ss. 37-39.

Yeşayahu, Natanel ben, Nuru'z-Zalâm, tahk. Yosef Kafih, ha-Aguda le-hatslat Ginzey Teyman, Yeruşalayim 1967. 


\section{MILEL VE NIHAL}

inanç, kültür ve mitoloji araştırmaları dergisi

Cilt/Volume: 11 Sayı/Number: 2 Temmuz - Aralık / July - December 2014

ISSN: 1304-5482

Bu dergi uluslararası EBSCO HOST Research Databases veri indeksi ve

TÜBITAK-ULAKBİM Sosyal ve Beşeri Bilimler Veri Tabanı tarafından taranmaktadır.

\section{Sahibi / Owner}

Milel ve Nihal Eğitim, Kültür ve Düşünce Platformu Derneği adına Şinasi Gündüz

$$
\begin{aligned}
& \text { Yazı İşleri Sorumlusu / Legal Representative } \\
& \text { Yasin Aktay }
\end{aligned}
$$

Editör / Editor

Şinasi Gündüz

Editör Yrd. / Co-Editor

Cengiz Batuk

Hakan Olgun

\section{Yayın Kurulu/ Editorial Board*}

Alpaslan Açıkgenç, Ayaz Akkoyun, Yasin Aktay, Mahmut Aydın,

Cengiz Batuk, Şinasi Gündüz, İbrahim Kayan, Hakan Olgun, Necdet Subaşı,

\section{Burhanettin Tatar}

\section{Danışma Kurulu/Advisory Board*}

Baki Adam (Prof. Dr., AÜ); Mohd. Mumtaz Ali (Prof. International Islamic U. Malezya); Adnan Aslan (Prof.Dr., Süleyman Şah Ü.); Kemal Ataman (Doç.Dr., Uludağ Ü.); Mehmet Akif Aydın (Prof. Dr., Marmara Ü.); Yılmaz Can (Prof. Dr., OMÜ); Ahmet Çakır (Doç. Dr., OMÜ); Mehmet Çelik

(Prof. Dr., Celal Bayar Ü.); Waleck S. Dalpour (Prof. University of Maine at Farmington); İsmail

Engin (Dr., Berlin); Cemalettin Erdemci (Prof.Dr. YYÜ); Tahsin Görgün (Prof.Dr., 29

Mayıs Ü.) Ahmet Güç (Prof.Dr., Uludağ Ü.); Recep Gün (Doç. Dr., OMÜ); Ö. Faruk Harman

(Prof.Dr., Mar.Ü.); Erica C.D. Hunter (Dr., Cambridge U.); Mehmet Katar (Prof. Dr., A.Ü.);

Mahmut Kaya (Prof. Dr., İ.Ü.); Sadık Kılıç (Prof.Dr., Atatürk Ü.); Şevket Kotan (Y.Doç.Dr., İ.Ü.); İlhan Kutluer (Prof.Dr., Mar. Ü.); George F. McLean (Prof. Catholic Univ., Washington DC); Ahmet Yaşar Ocak (Prof. Dr., Hacettepe Ü.); Jon Oplinger (Prof. University of Maine at Farmington); Ömer Özsoy (Prof.Dr., Frankfurt U.); Roselie Helena de Souza Pereira (Mestre em

Filofia-USP; UNICAMP Brasil); Ekrem Sarıkçıŏlu (Prof.Dr., SDÜ); Hüseyin Sarıoğlu (Prof.Dr.,

İÜ); Bobby S. Sayyid (Dr. Leeds U.); Mustafa Sinanoğlu (Prof.Dr., 29 Mayıs Ü.); Mahfuz Söylemez

(Prof.Dr. IÜ); Necdet Subaşı (Y.Doç.Dr., DİB); Bülent Şenay (Prof.Dr., UÜ); İsmail Taşpınar

(Prof.Dr. Mar.Ü.); C. Sadık Yaran (Prof.Dr., OMÜ); Ali Murat Yel (Prof.Dr., Fatih Ü.); Hüseyin Yılmaz (Doç.Dr., YYÜ); Ali İhsan Yitik (Prof. Dr., DEÜ)

* Soyadına göre alfabetik sıra / In alphabetical order

\section{Kapak ve Sayfa Tasarımı / Cover \& Page Design} İnan Avc1

Baskı / Publication

Ladin Ofset - İstanbul, Haziran 2015

2.Mat. Sit. 3 NB 15 Topkapi İstanbul / İsmail Tüz 02125012418

Yönetim Yeri / Administration Place

Milel ve Nihal Eğitim, Kültür ve Düşünce Platformu Derneği

Fevzipaşa Cad. Şehit Mehmet Sarper Alus Sok. No: 5, K.: 3, Tel: (0212) 5339731 Fatih/İstanbul www.milelvenihal.org e-posta: dergi@milelvenihal.org

Milel ve Nihal yılda iki sayı olarak altı ayda bir yayımlanan uluslararası hakemli bir dergidir. Milel ve Nihal' de yayımlanan yazıların bilimsel ve hukuki sorumluluğu yazarlarına aittir. Yayım dili Türkçe ve İngilizce'dir. Yayımlanan yazıların bütün yayın hakları Milel ve Nihal'e ait olup, yayıncının izni olmadan kısmen veya tamamen basılamaz, çoğaltılamaz ve elektronik ortama taşınamaz. Yazıların yayımlanıp yayımlanmamasından yayin kurulu sorumludur. 


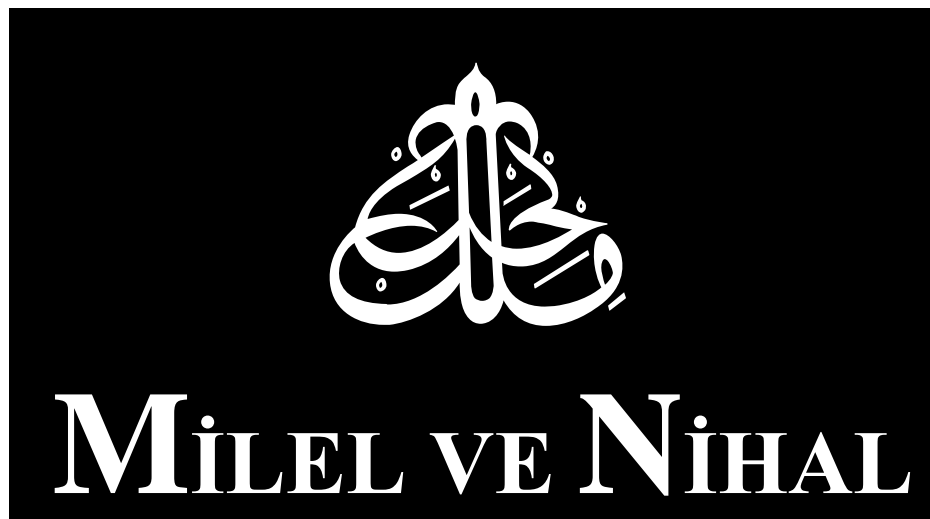

inanç, kültür ve mitoloji araştırmaları derogisi

ISSN: 1304-5482

Cilt/Volume: 11 Sayı/Number: 2

Temmuz - Aralık / J uly - December 2014 


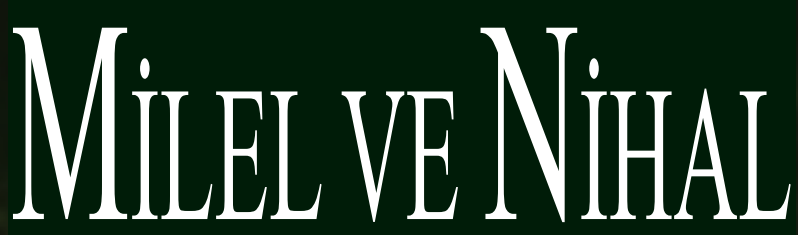

inanç, kültür ve mitoloji araştırmaları dergisi

ISSN 1304-5482

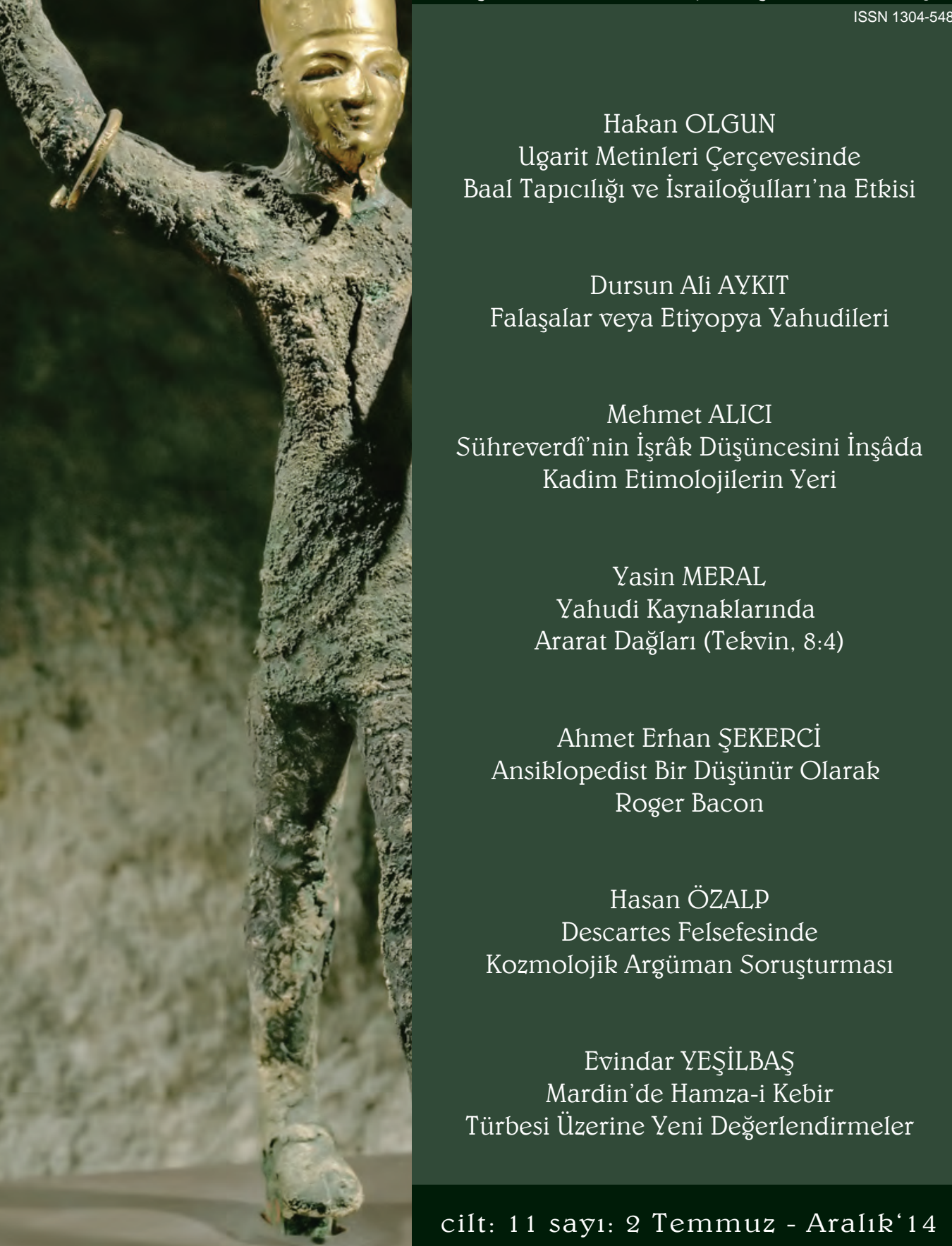

